\title{
TRABALHO COLETIVO TRANSMUTADO EM AJUDA: (A CONTRIBUIÇÃO DA CRIANÇA À SOBREVIVÊNCIA FAMILIAR NA ATUALIDADE) ${ }^{1}$
}

Soraya Franzoni Conde ${ }^{2}$

Resumo: Esta pesquisa é sobre a exploração infantil no trabalho, na atualidade, e procura caracterizá-la e mapeá-la por meio de pesquisa realizada junto ao Hospital Infantil Joana de Gusmão (HIJG). Nosso objetivo é problematizar investigações atuais sobre o objeto em questão e indicar direções para trabalhos futuros. A investigação foi realizada com entrevistas semiestruturadas feitas a 106 responsáveis imediatos por crianças, entre cinco e 15 anos, atendidas na emergência do HIJG. A apreensão do fenômeno exigiu que ultrapassássemos sua aparência imediata, localizando a criança no contexto das relações sociais capitalistas. Não foi perguntando diretamente sobre o trabalho que descobrimos o trabalho infantil, mas caracterizando a ajuda infantil familiar. Concluímos que a exploração da criança no trabalho ocorre em espaços pulverizados integrando o trabalho social abstrato, qualitativamente diferente do que ocorria nos primórdios da Revolução Industrial.

Palavras-chave: Exploração infantil no trabalho. Trabalho social abstrato. Trabalho ajuda. 


\section{Introdução}

As pesquisas contemporâneas sobre a exploração infantil no trabalho têm se deparado com alguns desafios. Os problemas envolvidos escapam das relações aparentes e imediatamente perceptíveis. Embora proibido pela legislação vigente, o trabalho da criança representa uma ajuda ao orçamento familiar ou, ainda, uma ação preventiva à malandragem, à vagabundagem, e ao uso de drogas.

$\mathrm{Na}$ fumicultura, por exemplo, as crianças, devido à baixa estatura, exercem várias atividades junto com a família. Elas são as responsáveis pela coleta da primeira folha do fumo: "o baixeiro". Nesse contexto, o trabalho infantil é defendido como educativo, uma vez que é necessário preparar-se desde cedo à inserção no trabalho. Essas faces contemporâneas e arcaicas do "aprender fazendo" evidenciam quão tênues são os limites entre o veto legal ao trabalho infantil e as formas toleráveis e necessárias de inserção da criança no trabalho.

De acordo com a concepção apologética ao trabalho, ajudar os pais, nos diversos serviços domésticos, como, por exemplo, fazer a cama, varrer a casa, dar trato aos animais ou cuidar dos irmãos não é considerada exploração infantil no trabalho. Evidentemente, nessa formulação, a referência é o trabalho enquanto uma categoria histórica, em geral, eterna necessidade humana e não o trabalho assalariado, pressuposto da acumulação capitalista, que produz valor excedente para outrem, não para si próprio.

Segundo dados oficiais, há 246 milhões de meninos e meninas trabalhando no planeta; desses, cerca de três milhões estão no Brasil, com 1,48 milhão de crianças trabalhando no campo e 1,49 milhão na cidade (PNAD/IBGE/2005).

Na região Sul do Brasil, 527.951 crianças trabalham e no estado de Santa Catarina, este número é de 112.057, o que corresponde, respectivamente, a $10 \%$ e $9,62 \%$ do total da população sulista e catarinense na faixa etária entre cinco e 15 anos. (PNAD/IBGE/2005). Se no Brasil a maior parte $(50,18 \%)$ do trabalho infantil é realizada na cidade, em Santa Catarina, esta tendência não é verificada, visto que $62,63 \%$ é efetivado por crianças e adolescentes que vivem na área rural. A maior parte destas crianças $(62,63 \%)$ não recebe remuneração uma vez que trabalham em regime familiar (PNAD/IBGE/2005). 
Desde 1990 as denúncias de exploração infantil têm aumentado e delas emergiram políticas públicas que procuram corrigir ou minimizar os resultados da baixa renda familiar. Todavia, os dados do governo federal brasileiro apontam que entre 1995 e 2002 houve uma redução de 41,95\% no número de crianças e adolescentes trabalhadores no país, na faixa etária de cinco a 15 anos. Em termos relativos, a taxa de crianças trabalhadoras diminuiu de $13,74 \%$, em 1995, para 8,22\%, em 2002. (Mapa de Indicativos do Trabalho da Criança e do Adolescente no Brasil, 2005).

A preocupação central da pesquisa realizada foi desenvolver uma forma de tornar cognoscível as relações sociais reais. Com base na investigação que realizamos entrevistando 106 famílias atendidas na emergência pediátrica do Hospital Infantil Joana de Gusmão, Florianópolis, SC, afirmamos que o trabalho infantil, assim como a dor de cabeça, constitui-se num problema atual invisível, porém real. Sua apreensão escapa das relações aparentes.

A pesquisa se orientou pelos seguintes pressupostos:

- Apesar do aumento das políticas públicas à erradicação do trabalho infantil, essas não têm constituído medidas eficazes para eliminar o trabalho da criança;

- A exploração infantil no trabalho vem aumentando, mas não é visível devido aos laços sociais que a encobrem;

- Toda coleta de dados e pesquisa evidencia pressupostos teóricos, epistemológicos e ontológicos, quer tenhamos consciência disso ou não. Trata-se, portanto, de tornar esse processo evidente;

- As denúncias atuais de exploração infantil no trabalho não estão mais no interior das fábricas.

\section{As pesquisas contemporâneas sobre a exploração infantil no trabalho}

Tomamos como base para nossa análise, a tese de Maurício Silva, publicada em 2003, sob o título Trama doce-amarga: (a exploração do) Trabalho Infantil e Cultura Lúdica; o resultado da tese de pós-doutoramento de Ana Lúcia Kassouf, publicada em 2007, com o título O que conhecemos sobre o trabalho infantil?; e, por último, a monografia de José Kauling, disponibilizada em 2008, com o título O trabalho Infantil na Cultura da Cebola no estado de Santa Catarina. 
Entre a vastidão de pesquisas analisadas na revisão bibliográfica, para efeitos deste texto, escolhemos os trabalhos indicados por se tratarem de pesquisas sérias, realizadas com rigor e coerência teórico-metodológica e por apresentarem características inovadoras em relação à maior parte de pesquisas existentes sobre o assunto.

Silva (2003), parte dos pressupostos do materialismo histórico dialético e realiza pesquisa na área educacional sobre o mundo do trabalho infantil e as representações presentes nas brincadeiras das crianças trabalhadoras da Zona da Mata nordestina.

Segundo o autor, a exploração infantil no trabalho, consolida-se no século $\mathrm{XIX}$, com o advento do capitalismo, quando Estado passa a manter as casas de trabalho que abrigavam crianças pobres, vadias e mendigas. Essa situação difere do trabalho medieval que se desenvolvia ao redor da casa e junto com a família, como do trabalho como princípio educativo, cujo objetivo é tornar as crianças aptas à satisfação de suas exigências pessoais. A infância negada pela exploração do capitalismo difere das diferentes atividades desenvolvidas pelas crianças para a organização da vida familiar.

$\mathrm{Na}$ atualidade, o capitalismo tem reforçado o problema da exploração, uma vez que a miséria e o desemprego são condições inerentes à lógica cumulativa e destrutiva do sistema social. $\mathrm{O}$ trabalho infantil é necessário à sobrevivência familiar e uma das formas das empresas manterem-se competitivas, reduzindo o preço da força de trabalho utilizada e, com isso, baixando o tempo necessário à produção de cada mercadoria. Ao baixar o tempo socialmente necessário à produção de cada mercadoria, com o desenvolvimento da tecnologia e das forças produtivas, reduz-se o preço final de cada produto. Por isso, concluí Silva, é preciso criticar a não radicalidade das políticas públicas e das organizações internacionais, como a UNICEF.

Para o autor, a condição assalariada, desenvolvida teoricamente e criticada exaustivamente desde Marx e Engels, nega a possibilidade da infância, do lazer, do tempo livre, da preguiça, da possibilidade de emancipação e dignidade, da distribuição social da riqueza e, até mesmo, do trabalho adulto regulamentado e explorado. Silva utiliza diversas fontes de pesquisa: jornais, revistas, documentos, cartas, desenhos, entrevistas (livres e informais, com cuidado especial, e diferença para com a criança), observações, fotografias (metáforas da realidade), oficinas. As técnicas de coleta de dados buscam fornecer pistas, auxiliar o recorte e a definição 
dos passos seguintes da pesquisa. Para isso, o pesquisador aguça, treina e sistematiza um método capaz de amiúde capturar a realidade.

Na pesquisa empírica desenvolvida por Silva (2003), o autor constatou as sequielas e os riscos que o trabalho infantil oferece à saúde física e emocional, pois as crianças deixam de viver situações lúdicas, ociosas e necessárias ao desenvolvimento equilibrado do ser humano, comprometendo a vida adulta. A pesquisa com crianças cortadoras de cana da Zona da Mata nordestina revela o envelhecimento precoce e a degeneração das condições objetivas de maturação e desenvolvimento. $\mathrm{O}$ autor percebe sinais pelo corpo, falha nos dentes, manchas pela pele, fala truncada, marcas e cicatrizes oriundas da manipulação de objetos cortantes, desnutrição, crescimento retardado, seqüelas biológicas, problemas de visão, calos nas mãos, dificuldades de aprendizagens, agressividade e falta de esperança. A perspectiva de vida dos trabalhadores da cana varia entre 43 e 45 anos.

Outro autor que consideramos exemplar é Kauling, (2008), que desenvolve pesquisa sobre o trabalho infantil no cultivo da cebola em Santa Catarina. Para apreender a exploração numa atividade cujo trabalho da criança está naturalizado, o autor pesquisa o cultivo da cebola, a forma como a criança se insere no processo de trabalho e os motivos que levam essa problemática a persistir. Sua pesquisa é feita com desenhos, observações, entrevistas (com crianças e adultos) e fotografias.

Primeiramente o autor compreende a produção da cebola, descrevendo o plantio e a colheita e as crianças acompanhando as famílias e "ajudando" no trabalho. Especificamente, na época de plantio, o trabalho da criança consiste em furar a terra com o dedo e colocar a semente. Esse processo é analisado por Kauling como altamente (des)educativo, pois a medida em que as crianças crescem e veêm a cebola crescer, elas desenvolvem um sentimento de compromisso com o trabalho e com o produto do trabalho.

A partir da análise dos dados coletados, Kauling evidencia que as famílias manifestam orgulho pelo trabalho da criança que aparece como algo natural. Aparentemente parecemos estar diante do trabalho familiar anterior ao desenvolvido pela sociedade capitalista. Mas, uma análise amiúde percebe que a cebola plantada não serve ao consumo próprio, mas ela é produzida para a troca e o valor da saca da cebola é determinado pelos atravessadores e não pelo agricultor individual. Tratase do trabalho coletivo, socialmente necessário. 
O autor também percebe que muitos adultos têm o trabalho invalidado pelo trabalho precoce exaustivo; o que os fazem dependentes do trabalho das crianças. Além disso, na roça as crianças estão expostas a todas as intempéries, condições climáticas e resíduos de agrotóxicos utilizados.

Kauling (2008), concluí que o trabalho infantil é uma forma histórica das crianças pobres aprenderem a se virar sozinhas. Quando vendem o produto do próprio trabalho recebem o dinheiro como recompensa e devem administrá-lo sozinhas. Esse processo interfere a formação da subjetividade da criança pobre, uma vez que ela cresce percebendo que é por meio do trabalho que sua condição de pobreza será resolvida.

A criança que trabalha, constata o autor, não falta à escola, mas também não tem tempo para estudar e nem para o lazer. As famílias não apoiam que as crianças deixem de trabalhar para estudar tanto porque necessitam imediatamente do produto do trabalho da criança, como porque isso contribuiria para influenciar os jovens a saírem do campo. Os adultos desejam que os jovens perpetuem suas tradições agrícolas de maneira bem sucedida, algo improvável para a agricultura familiar catarinense.

Kauling (2008) concluí corroborando a tese de ciclo da pobreza e apontando a solução do trabalho infantil por meio do avanço da escolarização, algo que acreditamos ser improvável uma vez que o trabalho infantil, assim como o desemprego, não depende da qualificação do indivíduo, mas sim de determinantes estruturais.

Kassouf (2007) apura as pesquisas atuais sobre o trabalho infantil e busca as causas, as consequiências e as soluções para a problemática. A autora entende que a ênfase atual nas pesquisas sobre a temática é oriunda na redução da pobreza e na visão de que o trabalho de crianças impede o progresso econômico. Além disso, a autora aponta as facilidades atuais para aquisição de microdados pelas tecnologias computacionais e as possibilidades de testar políticas eficientes por meio de programas de computação. A autora também corrobora a tese do ciclo da pobreza, uma vez que já na primeira página do seu texto afirma: "As principais consequiências socioeconômicas do trabalho de crianças e de adolescentes são sobre a educação, o salário e a saúde dos indivíduos" (Kassouf, 2007, p 323).

Kassouf (2007) mapeia os autores que abordam o trabalho infantil, principalmente aqueles que apontam na escolarização e no avanço das políticas públicas a solução às mazelas sociais. Entretanto, não aprofunda 
a análise e nem percebe as contradições inerentes ao sistema capitalista. O desemprego, o trabalho infantil e o valor do salário não são determinados pela qualificação e pela escolaridade do indivíduo, mas pela lógica capitalista que tende a maximizar a exploração da mais-valia por meio da redução do capital variável (força de trabalho) e da ampliação do capital constante. Dessa forma, desemprego e exploração barata de força de trabalho serão sempre tendências presentes no modo de produção capitalista.

A autora afirma que as crianças não deixam de trabalhar porque o salário representa um ganho imediato e a escola representa um ganho futuro. As pessoas não conseguem esperar e precisam consumir no presente. Caso, a família tivesse mais acesso ao crédito, seria mais provável que colocasse o filho na escola, define Kassouf. As causas do trabalho infantil são: pobreza, escolaridade, tamanho da família, sexo do chefe familiar, local de residência. Seguindo exemplo de China, Tailândia, Índia e Vietnã, Kassouf concluí que o aumento do PIB (Produto Interno Bruto) diminui o trabalho infantil. Por meio de fórmulas econométricas, a autora explícita as variáveis causais do trabalho infantil, entretanto se perde ao não aprofundar as relações sociais capitalistas e as especificidades presentes por tras de regras e equações matemáticas generalizantes.

\section{Quando o trabalho da criança torna-se um problema}

Com a mesma delicadeza de consciência observaram os fabricantes de vidro que não era possível conceder aos meninos refeições regulares, porque se perderia, se desperdiçaria determinada quantidade de calor que os fornos irradiam. [...] Os meninos trabalham nos fornos que fazem garrafas e flin,t andam durante a execução de seu trabalho ininterrupto, 15 a 20 milhas inglesas em 6 horas. E o trabalho dura freqüentemente 14 a 15 horas. [...] O tempo que resta realmente para repouso é extremamente curto. Não sobra tempo para diversão, para respirar ar puro, à custa do sono tão indispensável aos meninos que executam um trabalho tão fatigante [...] Enquanto isso ocorre, talvez tarde da noite, o dono da fábrica de vidros, cheio de abstinência e de vinho do porto, sai do clube para casa, com passos incertos, cantarolando imbecilmente: britons never shallbe slaves! (Nunca jamais os ingleses serão escravos!) Childrens's Employment Comission. Fourth Report, 1865. (MARX, 1968, p. 299) 
A noção de exploração no trabalho e, sobretudo, infantil, advém dos estudos fundamentados em Karl Marx, que se referem ao trabalho na forma assalariada e na grande fábrica, desenvolvidos no final do século XVIII na Inglaterra. Para este autor, a exploração infantil no trabalho, sinônimo de "meia força de trabalho", explica-se desde que considerada não em si mesma, mas em relação ao contexto social que assegurou a instituição do trabalho social coletivo.

A emergência da sociedade burguesa e a incorporação da maquinaria criam condições à incorporação de crianças no trabalho industrial. Enquanto o trabalho medieval se desenvolve ao redor da casa e junto à família; na modernidade capitalista emerge a individualidade e o trabalho passa a ser realizado em locais específicos e distantes do cotidiano familiar. As crianças são coercitivamente incorporadas ao processo de trabalho fabril, junto da divisão social do trabalho e da introdução das máquinas. O homem transforma-se em mero acessório da máquina, os salários são comprimidos, a produção é otimizada e os trabalhadores tornam-se descartáveis.

A introdução da iluminação nas fábricas, realizadas primeiramente a gás, por exemplo, alonga a jornada de trabalho e permite, homens, crianças e mulheres trabalharem à noite. A dispensa da força muscular, assegura a apropriação do trabalho de crianças e de mulheres, aumenta o número de assalariados e confere a todos os membros familiares a qualidade de trabalhadores produtivos, sem limitações legais ou humanas à exploração. O saber, antes propriedade do trabalhador, passa a ser propriedade do capitalista, representada na maquinaria. O capital variável (força de trabalho) torna-se capital constante. $\mathrm{O}$ trabalhador homem, experiente $\mathrm{e}$ forte torna-se descartável. Agora qualquer ser humano pode trabalhar, até mesmo mulheres e crianças.

As antigas e longas formas de aprendizagens caem em desuso. Neste sentido, Marx analisa anúncios de contrato que chamavam meninos e meninas de 12 anos para trabalharem desde que tivessem aparência de mais de 13:

crianças com menos de 13 anos só podem trabalhar seis horas. Um médico [...] tem que atestar a idade. $\mathrm{O}$ fabricante pede jovens que aparentem já ter 13 anos. [...] No mal-afamado distrito londrino de Bethnal Green, a cada segunda e terça-feira pela manhã, é realizado um mercado público, em que crianças de ambos os sexos, a partir dos 9 anos de idade, alugam a si mesmas para manufaturas de seda 
londrinas [...] os contratos são válidos por uma semana [...] Apesar da legislação, pelo menos 2 mil jovens continuam sendo vendidos por seus próprios pais como máquinas vivas para limpar chaminés [...] Toda vez que a lei fabril limita a seis horas o trabalho infantil em ramos industriais até então não atingidos, ecoa sempre de novo a lamentação dos fabricantes: que parte dos pais retiraria as crianças da indústria agora regulamentada, para vendê-las naquelas onde ainda predomina a liberdade de trabalho, isto é, onde crianças com menos de 13 anos são obrigadas a trabalhar como adultos, podendo, portanto, serem alienadas a um preço maior (MARX, 1988, p. 22).

Ainda no século XIX, a partir de denúncias e de relatos das atrocidades cometidas com adultos e crianças no trabalho na grande indústria, surgiram as primeiras legislações que impuseram limite à voracidade capitalista. A exploração desenfreada era característica típica de alguns ramos da atividade econômica, enquanto que em outros havia restrições legais à exploração da força de trabalho, como sugere o relatório:

Para nosso estudo basta extrair alguns depoimentos de crianças exploradas, encontradas nos relatórios de 1860e 1863. Pelo que ocorre com as crianças pode-se deduzir o que se passa com os adultos, principalmente meninas e senhoras, numa indústria ao lado da qual a fiação de algodão e outras atividades semelhantes pareceriam agradáveis e sadias. Wilhelm Wood, um garoto de nove anos, "tinha sete anos e 10 meses de idade, quando começou a trabalhar". Lidava com fôrmas (levava a mercadoria à câmara de secagem para apanhar depois, de volta, as fôrmas vazias) desde o início. Chega, todo dia da semana, no trabalho, às 6 horas da manhã e acaba sua jornada por volta de 9 horas da noite. "Trabalho até às 9 horas da noite, todo dia da semana. Assim, por exemplo, durante as últimas 7 a 8 semanas". Quinze horas de trabalho por dia para um garoto de sete anos! J. Murray, um menino de 12 anos depõe: "Lido com fôrmas e faço girar a roda. Chego ao trabalho às 6 horas da manhã, às vezes às 4 . Trabalhei a noite toda passada, indo até às 6 horas da manhã. Não durmo desde a noite passada. Havia ainda oito ou nove garotos que trabalhavam durante toda a noite passada. Todos menos um voltaram esta manhã. Recebo por semana 3 xelins e 6 pences. Nada recebo a mais por trabalhar à noite. Na semana passada trabalhei duas noites (MARX, 1968, p. 276-7). 
As longas horas de trabalho são evidências constatadas entre o trabalho infantil que, combinadas com insalubres condições de trabalho, são capazes de empestear crianças desde os seis anos de idade na produção de fósforo:

A fabricação de fósforos de atrito data de 1833, quando se inventou o processo de aplicar o fósforo ao palito de madeira. Desde 1845 desenvolveu-se rapidamente na Inglaterra, espalhando-se das zonas mais populosas de Londres, para Manchester, Birmingham, Liverpool, Bristol, Norwich, Newcastle e Glasgow e com ela floresceu o trismo, que segundo descoberta de um médico de Viena já em 1845, é doença peculiar dos trabalhadores dessa indústria. A metade dos trabalhadores são meninos com menos de 13 anos e adolescentes com menos de 18. Essa indústria é tão insalubre, repugnante e mal afamada que somente a parte mais miserável da classe trabalhadora, viúvas famintas, etc., cede-lhes seus filhos, "Crianças esfarrapadas, subnutridas, sem nunca terem frequientado a escola. Entre as testemunhas inquiridas pelo comissário White (1863), 270 tinham menos de 18 anos, 40 menos de 10, 10 apenas oito e cinco, apenas seis. $\mathrm{O}$ dia de trabalho variava entre 12, 14 e 15 horas, com trabalho noturno, refeições irregulares, em regra no próprio local de trabalho, empestado pelo fósforo. Dante acharia que foram ultrapassadas nessa indústria suas mais cruéis fantasias infernais. (MARX, 1968, p. 278).

Os estudos de Marx apontam para a exploração infantil no trabalho no interior das fábricas na primeira metade do século XIX. Essa parece ser uma das diferenças de seus estudos em relação à atualidade. Entretanto, conforme os resultados de nossas pesquisas, cenas dantescas semelhantes não são raras.

Em relação ao caso brasileiro, os primeiros relatos do trabalho infantil ocorrem na escravidão. Os filhos dos escravos acompanhavam seus pais nas mais diversas atividades em que eram utilizados e, assim, acabavam exercendo tarefas cuja exigência era superior às limitações físicas das crianças.

No início da industrialização do Brasil, também encontramos evidências da existência de trabalho infantil. Em 1890, o Departamento de Estatística e Arquivo do Estado de São Paulo registrava que 1/4 da força de trabalho empregada no setor têxtil era formada por crianças e adolescentes. Vinte anos depois o mesmo dado chega a 30\%. Em 1919, dados do Departamento Estadual do Trabalho, apontam 37\% dos 
trabalhadores do setor têxtil paulista sendo compostos por crianças e adolescentes e na cidade de São Paulo o índice chega à 40\% (OIT, 2001).

Contrariando as perspectivas otimistas em relação ao progresso capitalista da humanidade, enfatizamos os resultados coletados em pesquisa realizada junto à emergência do Hospital Infantil Joana de Gusmão, descritos a seguir. Ressaltamos a metodologia pioneira empregada para detectar casos de crianças que trabalham. Trata-se de ir além da aparência de dados governamentais e de informações isoladas acerca da erradicação do trabalho infantil no Brasil e em Santa Catarina. É preciso perguntar se a criança ajuda a sua família e detalhar minuciosamente a atividade de ajuda desenvolvida, apreendendo as relações entre a atividade individual da criança, a condição de vida familiar e as relações da sociedade capitalista. Com isso, indagamos: o que acontece à lata que a criança cata?

\section{Aspectos metodologicos da pesquisa}

As primeiras investigações realizadas em campo foram fundamentais para o desdobramento desta investigação e para a elaboração de um instrumento de pesquisa articulado com os pressupostos teóricos do materialismo histórico dialético. Para o materialismo histórico, a sociedade é uma rede de relações sociais e o indivíduo é por ela determinado. O ser social se encontra em condições objetivas que lhe foram dadas, e que pode transformá-las. Coerentemente com esse pressuposto tentamos focar a criança não como sujeito isolado, que possui direitos sociais, independentemente do contexto e das relações de classe da família em que está inserida. Trata-se de localizar a exploração do trabalho infantil na condição de exploração familiar. Apreender a realidade concreta exige sair da aparência imediata, capturando as relações existentes entre o objeto específico da pesquisa e a dinâmica social geral.

Para os pais das crianças trabalhadoras que, em geral, são de baixa renda, trabalho infantil é assunto proibido. A criança "ajuda" a família e é, por meio dessa ajuda, que atividades consideradas nocivas, como coletar lixo, trabalhar no tráfico, na fumicultura, são mantidas. Percebendo as maneiras de ocultação do caráter de exploração da criança, selecionamos procedimentos metodológicos para apreender suas relações: 
- Apreender, por meio de entrevistas, o contexto que deu origem ao motivo de procura de uma emergência hospitalar ("o que aconteceu com a criança?");

- Dimensionar o que a criança faz quando não está na escola (o que ela faz no período oposto ao da escola? O que ela faz à noite? O que ela faz nos finais de semana?);

- Qualificar a inserção da criança no trabalho (Que atividades são desempenhadas pela criança? Que tipo de ajuda executa? Descrição da consistência das atividades desenvolvidas. Com que frequiência ela executa a tarefa? Em que horários? Onde? Como? Por quê? Para quê?);

- Caracterizar o contexto sócio-econômico e familiar (Qual é a profissão dos responsáveis? Qual é a renda familiar? Em que bairro reside? Em que tipo de moradia vive? Com quem mora em casa? Quantos irmãos tem, o que fazem e quais são as suas idades? Recebe algum tipo de bolsa do governo federal?).

\section{A pesquisa no HIJG}

A pesquisa de campo desenvolveu-se no HIJG (Hospital Infantil Joana de Gusmão), localizado no município de Florianópolis, SC, com familiares de crianças atendidas na emergência pediátrica. Questionando as reduções anunciadas como produto do sucesso de políticas públicas eficientes, escolhemos realizar a pesquisa num local capaz de encontrar a criança no contexto familiar. Toda criança é levada ao hospital por um adulto responsável, o que permite capturar as condições de vida da família. Além disso, o HIJG é uma referência em atendimento hospitalar no estado de Santa Catarina, e oferece serviços nas seguintes especialidades: Alergologia, Cardiologia, Cirurgia Cardíaca, Cirurgia Pediátrica, Gastroentereologia, Genética, Hebeática, Hematologia, Infectologia, Nefrologia, Neonatologia, Neurocirurgia, Neurologia, Nutrologia, Odontologia, Bucomaxilofacial, Pediatria Geral, Pneumologia, Psicologia, Reumatologia, Terapia Intensiva e Urologia.

No início da pesquisa, pretendíamos encontrar crianças trabalhadoras perguntando diretamente para seus pais: a criança trabalha? Para nossa surpresa não encontramos nenhuma criança que trabalha perguntando diretamente sobre o assunto. Como exemplo da 
necessidade de revisão dos procedimentos de pesquisa, evidenciamos o momento em que duas adolescentes entram na emergência do hospital acompanhadas de um menino de oito anos e de um bebê de um mês. Os motivos da procura de atendimento são febre e gripe. Ao nos aproximarmos, para a realização da entrevista, a menina-mãe sorri e conta parte de sua vida:

Meu irmão tem oito anos e está com febre. Eu tenho 14 anos, mas já tenho um filho. Este é meu irmão, está na segunda série e eu não estudo mais [...] Tenho sete irmãos. Meu pai é pedreiro e minha mãe é faxineira [...] Eu também faço faxina na casa das pessoas. Meu irmão é ótimo aluno e cata latas na rua para vender junto com meu outro irmão mais novo [...]

Essa minha queimadura no rosto? Aconteceu quando eu ainda tinha seis anos. A conta de energia elétrica da minha casa tinha sido cortada. Meu pai fez uma lamparina de querosene e quando ele foi botar em cima do fogão, para iluminar a cozinha, pois queria esquentar a água, um de meus irmãos passou correndo e bateu na lamparina e o óleo caiu no meu pescoço, no peito e no braço pegando fogo $[\ldots]$

Essa minha irmã? Ela tem 16 anos e tem esse bebê de um mês que está com febre [...] Ela estudou até a $7^{\mathrm{a}}$ série e abandonou a escola, pois ficou grávida. Ela trabalha com a mãe, na faxina. Meus outros irmãos mais velhos ajudam o pai que é pedreiro. Ainda tenho outra irmã que também faz faxina.

Com dinheiro recebido ajudamos a pagar as contas da casa e, às vezes, compramos uma roupinha ${ }^{3}$

Foi em depoimentos como o acima citado, que apreendemos a necessidade de revisão dos procedimentos metodológicos. Não conseguimos identificar nenhum caso de acidente de trabalho infantil. A exceção deu-se apenas com o relato de um médico plantonista que nos disse ter atendido, recentemente, uma criança, às duas horas da madrugada, em virtude de uma bala perdida. Onde estava essa criança? Segundo o plantonista, ela guardava carros nas proximidades de uma pizzaria no bairro da Trindade, em Florianópolis, SC, Brasil. 
Percebemos, então, que a criança que trabalha chega ao hospital acompanhando seus irmãos e procura atendimento para doenças típicas infantis. Portanto, o trabalho da criança encontra-se entranhado na vida cotidiana de determinados segmentos da população sendo, por sua vez, percebido como natural. $\mathrm{O}$ trabalho infantil não ocorre isoladamente $\mathrm{e}$ para visualizá-lo é preciso apreender as relações em que está inserido, relacionando o que é imediatamente perceptível (no caso dessa pesquisa, o motivo de procura do atendimento hospitalar) com as relações que o engendram (as condições de vida familiar). De acordo com os dados coletados, a manifestação aparente de acidente ou de doença é apenas a ponta de um imenso "iceberg", pois a patologia infantil não está descolada das condições de vida e esta, muitas vezes, é quem determina aquela. De que adianta um remédio para coceira, se ao voltar para casa, a criança continuará catando lixo todos os dias, pois é da venda do lixo que ela, sua mãe e seus cinco irmãos sobrevivem?

A criança não trabalha, mas apenas "ajuda" a mãe a catar lixo no período oposto à escola. Para apreender esta ordem de relações indagamos sobre o que a criança faz no período em que não está na escola, qual o contexto familiar, a vida da criança, suas atividades de rotina na casa e na escola, o bairro, a profissão dos pais, a idade. Percebemos que na atualidade a exploração infantil no trabalho ocorre em espaços de serviços em geral e, principalmente, nos domésticos como ilustra a síntese da entrevista a seguir:

Ele pegou bicho de pé no quintal de casa. Lá em casa tem muito. Ele está com quatro bichos bem inflamados no mesmo pé. [...] Ele não gosta de estudar muito não, mas é um excelente ajudante. É meu braço direito em casa. Cuida das irmãs, vai à escola pela manhã, leva e busca as irmãs na escola, chega da escola, esquenta a comida, dá almoço, lava a louça, limpa o quintal, limpa a sujeira dos cachorros, varre a casa e arruma os quartos. Faz tudo o que precisamos até minha esposa chegar [...] Minha esposa faz faxina todos os dias até às 17 horas e eu sou pedreiro [...] Depois disso ele pode brincar. Ele gosta mesmo é de jogar bola.

No final de semana ele faz as tarefas da escola e as outras coisas da casa [...]

Quando aparece alguma coisa que dá para o menino fazer e minha esposa está sem faxina, eu o levo para me ajudar'. 
Por meio da constatação de situações como essa é que percebemos a importância de desvelar os véus sociais que encobrem a exploração infantil no trabalho que, na atualidade, encontra-se disperso nas mais variadas formas de trabalho. Prosseguindo nas indagações indiretas perguntamos o que o irmão da criança levada ao hospital faz quando ele não está na escola e obtivemos resultados significativos, pois $78 \%$ das crianças abordadas têm irmãos menores de idade que trabalham ou "ajudam". Em termos relativos, identificamos $32 \%$ de irmãos que trabalham em caráter de ajuda sistemática nas tarefas da casa, cuidando de outros irmãos ou de outras crianças, ajudando na roça ou no trabalho dos pais e $15 \%$ de irmãos trabalhadores do comércio, da rua, da limpeza, da construção civil e da coleta de materiais recicláveis. Dos $15 \%$ de irmãos trabalhadores do comércio, dois casos estão no comércio de drogas nos morros da região central de Florianópolis, SC, e um na produção e no comércio de calçados do município de São João Batista, SC, Brasil.

A exploração infantil no trabalho tem inúmeros véus. A criança não sofre acidente de trabalho, pois este é visto como salutar ajuda. Assim, quando se pergunta o que a criança faz enquanto não está na escola, o que era imperceptível ganha notoriedade. A criança não está mais na grande indústria do século XIX, ela está nas ruas, no morro e em casa - espaços de difícil averiguação. Ela vende mercadorias, lava, passa, cozinha, limpa e cuida das crianças mais novas. Nesta pesquisa, foram identificados contextos em que a criança é a única responsável pelo trabalho geral da casa, do cuidado de irmãos, de outra criança, de auxílio no trabalho não-doméstico junto aos pais, e ainda, em serviços de limpeza, de construção civil e na coleta de materiais recicláveis. Estas formas de trabalho não se apresentam de imediato, como assalariada, o que poderia nos levar a concluir que não é trabalho. Entretanto, imaginemos se estes trabalhos fossem exercidos por babás e faxineiras que recebessem remuneração, qual deveria ser o salário do pai ou da mãe que provê o sustento familiar?

Ilustrações são feitas com o exemplo a seguir, onde uma mãe se manifesta inconformada com o fato de o filho apresentar fratura oriunda de um jogo de futebol, no domingo: 
Agora estou perdida, ele é quem cuida da roupa, da louça e da comida da casa. É meu braço direito. Todos os dias ele tem que chegar da escola, fazer as tarefas da casa e depois estudar. Só o libero para brincar durante os finais de semana. Agora estou muito preocupada, pois quem vai fazer o serviço da casa? Além de não me ajudar, ele ainda me dará trabalho e gastos ${ }^{5}$.

A irmã do garoto fraturado, que chora durante a entrevista, complementa o depoimento da mãe dizendo que não pode encontrar os amigos para jogar bola. A mãe diz: "Não liga não, ela é mal humorada mesmo! Fazer o quê se a gente tem que trabalhar?".

Segundo o IBGE (PNAD, 2001), o Brasil possui 494.002 crianças e adolescentes entre cinco e 17 anos que trabalham como domésticas e, na sua maioria, são entendidas como ajudantes. O trabalho infantil doméstico é apenas uma das manifestações da exploração da criança, resultante da condição sócio-econômica precária da família que não pode pagar serviços de uma empregada doméstica, de creche ou de babá, enquanto o responsável trabalha fora.

Situações exemplares de precarização no trabalho não são raras. Entrevistamos uma mãe que procura atendimento para a filha de nove anos com coceira e feridas pelo corpo:

Eu tenho estes cinco filhos, além de um menino de 13 anos que está com a avó no Paraná. Ele mora com minha mãe porque eu não consegui criá-lo. Morro de saudade dele. Minha mãe diz que ele é bom, pois estuda de dia e de noite trabalha cuidando de carros no centro da cidade de Clevelândia, no Paraná. Eu não me lembro em que série da escola ele está.

Para sustentar essas crianças eu coleto lixos recicláveis na rua. Levo sempre meus cinco filhos comigo [...]

A menina mais velha, de nove anos, cata lixo e também limpa a casa, é um brilho só.

No ano passado eu juntei um dinheiro e consegui comprar um carro para a coleta de recicláveis. Encho cinco carros por dia: três durante a manhã, com ajuda das crianças e apenas dois à tarde quando fico sozinha, pois elas vão à escola. O Conselho Tutelar vive me dando bronca porque as crianças andam comigo na rua. 
Mas, tem escola o dia todo? E depois se nós não trabalharmos, passaremos fome. Eu recebo cerca de $\mathrm{R} \$ 130,00$ por mês com a venda de recicláveis. Recebo, também, duas bolsas do PETI.

Há 15 dias estou sem gás de cozinha e todo dia tenho que fazer fogueira para cozinhar. Consegui juntar $R \$ 10,00$, mas faltam $R \$ 25$, 00. Por isso, vim até aqui a pé com as crianças. Os pais delas não me ajudam em nada [...]

Esse meu filho tem sete anos, aos seis sofreu queimadura enquanto eu esquentava água. Estava frio e as crianças sentaram-se perto do fogo. Ele queimou a mão tentando pegar feijão para comer [...] Eles morrem de vontade de terem brinquedos das lojas bonitas, mas temos que nos contentarmos com o que achamos no lixo. Não consigo nem comprar roupas. Cada mês eu compro uma coisa para um: uma escova de dente, um tênis, uma calça. Não dá para comprar para todos no mesmo mês. No ano passado ganhei uma televisão e uma geladeira no programa do César Souza. Recebo também doação de vizinhos e de conhecidos [...]

Tenho muita vontade de trazer meu filho mais velho (choro). Mas ele é adolescente e o bairro que moramos, Aparecida de Coqueiros tem muita droga, traficante e tiroteio. Tenho medo que ele se envolva. Não os deixo sozinhos em casa. Vamos todos juntos, aonde eu vou, vamos os cinco juntos. Já tive quatro maridos, tive filho com todos e nunca mais quero casar para não ter que ficar cuidando, sozinha, dos filhos (choro). ${ }^{10}$

A manifestação de coceira em uma das crianças foi o pretexto de entrada ao hospital, entretanto, ele escamoteia as condições em que os materiais recicláveis são coletados. O que adianta receitar uma pomada se, ao voltar para casa, a criança continuará catando latas e mexendo com lixo? Evidenciamos, portanto, a criança em seu contexto e a necessidade de uma leitura sociológica dos atendimentos hospitalares. Para os médicos plantonistas, a relação entre a coceira e o trabalho não existe; já para o pesquisador social ela só existirá se ele conseguir descobrir que, embora a criança afirme que não trabalhe, no período oposto à escola ela "ajuda" sua mãe a encher cinco carros de lixo reciclável. Ao contrário de grande parte das pesquisas atuais, a essência da exploração das crianças está na materialidade das relações sociais. 
A redução dos focos concentradores de crianças que trabalham as exemplares grandes indústrias do século XIX - coincidem com o aumento da exploração em espaços ilícitos, pulverizados e de difícil visualização, onde se encontram as crianças que trabalham para o tráfico de drogas. $\mathrm{O}$ fenômeno, até então conhecido como próprio de morros cariocas, apresenta-se, também em Florianópolis, que tem vivenciado o aumento da população e o inchamento das favelas, conforme vemos no depoimento a seguir:

Eu me separei porque meu primeiro marido me batia tanto. Batia em mim e nas minhas crianças. Sofri muito. Um dia, meus vizinhos chamaram a polícia e então eu me separei [...].

No início os meninos mais velhos ficaram com o pai. Até que descobri que os três trabalhavam para o tráfico de drogas. Eles tinham arma, pulavam o muro da escola todos os dias. Eles moravam com o pai no Morro da Caixa. Fiquei doida e levei os dois mais velhos para morarem com meu pai, em Lages. Meu pai é agricultor e planta fumo. Os meninos estão trabalhando com ele. Por enquanto, não vão mais à escola, pois é muito longe. Meu ex-marido é faxineiro da polícia militar. Minha vida é muito difícil ${ }^{6}$.

Conforme o relatório publicado pela ANDI/ março de 2005, cerca de seis mil crianças e adolescentes vivem sob o risco iminente de morte, pois trabalham no tráfico de drogas. As crianças são preferidas porque têm coragem e agilidade junto às armas de fogo, fuzis, metralhadoras, pistolas e granadas. Elas lutam contra a polícia e contra facções rivais, sem temor em relação às conseqüências. $O$ tráfico de drogas é um ramo extremamente lucrativo, pois não paga imposto sobre a mercadoria, nem os direitos trabalhistas de seus empregados e o valor final, agregado ao produto, chega a mais de $1000 \%$.

\section{Considerações finais}

A apreensão da exploração infantil no trabalho e a sua caracterização na perspectiva do materialismo histórico dialético exigem uma investigação que, diferentemente de estudos quantitativos e utópicos 
realizados por organizações governamentais, não-governamentais e diversos autores, busca sair da aparência imediata e apreender a criança em suas relações sociais.

Assim, durante a pesquisa de campo e a elaboração do instrumento piloto de pesquisa, não alcançamos nossos objetivos perguntando diretamente por ele, mas investigando a rotina e o contexto familiar. Não encontramos nenhum caso de trabalho infantil perguntando diretamente por ele. A mudança do foco, que se descolou do cotidiano aparente e imediato, permitiu à nossa investigação dar uma guinada. Passamos, portanto, a estabelecer relações entre as necessidades da família, a rotina, a ajuda e a exploração no trabalho.

Onde termina a ajuda da criança e começa a exploração é uma questão que nos desafia. Entretanto, a ênfase no contexto revela as diferenças entre cantar no chuveiro e cantar numa casa noturna. Aparentemente trata-se da mesma atividade isolada. Entretanto, à medida que a atividade da criança se dirige à troca por um salário ou ocupa o trabalho/emprego de outro adulto, recebe conotação diferente. É preciso olhar o contexto em que a criança está situada. É preciso ver o todo e as partes. O ser criança, a atividade de ajuda desenvolvida e as relações com o modo de produção capitalista.

Tendo em vista a elaboração do plano piloto de pesquisa, indicamos algumas considerações sobre os aspectos mais importantes na apreensão da realidade. A exploração infantil no trabalho, na atualidade, é transmutada em "ajuda" e difere do trabalho fabril, realizado nos espaços concentrados atestados por Marx e Engels, no século XIX. A criança trabalha na rua, no serviço doméstico, na agricultura, na venda de drogas e na venda do corpo, compondo o trabalho coletivo. A dificuldade encontrada para coletar esses dados reflete a invisibilidade do trabalho social abstrato, em um estranhamento individual, coletivo e material.

Finalmente, para prosseguir, indicamos algumas questões que devem ser agregadas ao estudo sobre as condições em que está ocorrendo o trabalho infantil: quantas horas as crianças estão trabalhando na atualidade? Quantas horas descansam? Quantas têm de lazer? Quantas horas os pais trabalham? Quantas horas descansam? Quantas horas têm de lazer? Por que a legislação coíbe o trabalho infantil, em alguns ramos da atividade econômica, enquanto que permite em outras? 


\section{Notas}

${ }^{1}$ Este texto foi produzido a partir de resultados da dissertação de mestrado intitulada Trabalho Invisível, defendida em 2007 no Programa de Pós Graduação em Sociologia Política da UFSC. O trabalho foi orientado pela professora doutora Bernardete Aued, a quem agradecemos imensamente.

${ }^{2}$ Doutoranda em Educação da UFSC, membro do Núcleo de Estudos sobre as Transformações no Mundo do Trabalho TMT/UFSC e do Projeto de Pesquisa Educação do Campo: políticas e práticas em Santa Catarina - Observatório da Educação/CAPES/ INEP.

${ }^{3}$ Fonte: entrevistas concedidas às autoras entre 15 e 30 de setembro de 2006.

${ }^{4}$ Fonte: entrevistas concedidas às autoras entre 15 e 30 de setembro de 2006.

${ }^{5}$ Fonte: entrevistas concedidas às autoras entre 15 e 30 de setembro de 2006.

${ }^{6}$ Fonte: entrevistas concedidas às autoras entre 15 e 30 de setembro de 2006.

\section{Referências}

AAMARAL, Carlos. A evolução do trabalho infantil no Brasil de 1999 a 2001. Artigo disponível em www.andi.org.br . Acesso em: 6 out. 2005 às $15 \mathrm{~h} 45$.

ANTUNES, Ricardo. "Os caminhos da liofilização organizacional: as formas diferenciadas da reestruturação produtiva no Brasil”. In: Idéias (Revista do Instituto de Filosofia e Ciências Humanas/UNICAMP), ano 9 (2) 10(1). Campinas, SP: IFCH/UNICAMP. 2003. (p. 13-24)

AUED, Bernardete W. Desemprego e Informalização. Artigo no prelo. UFSC. 2005.

BRASIL, Ministério do Trabalho e do Emprego. Mapa de Indicativos do Trabalho da Criança e do Adolescente no Brasil. 1.ed. Brasília: MTE. 2005.

CONDE, Soraya F. Trabalho Invisível. Florianópolis, SC. 2007. Dissertação (mestrado em Sociologia Política). Programa de Pós-graduação em Sociologia Política/CFH. Universidade Federal de Santa Catarina.

FOLHA DE SÃO PAULO. "Trabalho infantil migra para o quintal”. In: Folha de São Paulo/ Caderno Cotidiano. São Paulo: domingo, 10 jul. 2005.

HARVEY, David. Espaços de esperança. São Paulo, Loyola, 2004. 
KAULING. José. O Trabalho Infantil na Cultura da Cebola no estado de Santa Catarina. (monografia do curso de especialização em Educação do Campo e Desenvolvimento Territorial Sustentável). Florianópolis, UFSC. 2008.

KASSOUF, Ana Lúcia. O que conhecemos sobre o trabalho infantil?. I: Nova Economia. Belo Horizonte, MG, Br. 17 (2) 323-350_maio_agosto de 2007. p. $323-352$.

MARX. Karl. O Capital: o processo de produção do capital. (Volume 1 Livro primeiro Tomo 1). São Paulo: Nova Cultural. 1988a.

O Capital: o processo de produção do capital. (Volume 1 Livro primeiro Tomo 2). São Paulo: Nova Cultural. 1988b.

. O capital. Rio de Janeiro: Civilização Brasileira, 1968.

NAVARRO, Vera. L. “A reestruturação produtiva na indústria de calçados de couro em Franca/SP”. In: Idéias (Revista do Instituto de Filosofia e Ciências Humanas/UNICAMP), ano 9 (2) - 10(1). Campinas, SP: IFCH/ UNICAMP. 2003. (p. 113 -174).

INSTITUTO OBSERVATÓRIO SOCIAL. "A idade da pedra: um ano depois”. In: Revista Observatório Social. Instituto Observatório Social, SP, $n^{\circ}$ 9, jan. 2006.

SILVA, Maurício R. da. Trama Doce-Amarga (exploração do) Trabalho Infantil e Cultura Lúdica. São Paulo: Hucitec, 2003.

SILVA, Reginaldo de S. O processo educativo de crianças trabalhadoras na rua. São Carlos, SP. 1997. Tese (doutorado em educação): UFSCAR/Centro de Educação e Ciências Humanas. Universidade Federal de São Carlos.

Sites consultados:

http://www.andi.org.br/tid/principal Acesso em: 25 set. 2004 às 10 h.

http://www.dieese.org.br/esp/ Acesso em: 21 nov. 2005 às 14 h. 
www.ibge.gov.br/pnad/trabalhoinfantil Acesso em: 6 maio 2005 às 10h50. http://www.ilo.org/public/portugue/region/ampro/brasilia/ Acesso em: 6 jun.2005 às $13 \mathrm{~h}$.

www.mte.gov.br/resultadosdafiscalizaçãodotrabalho. Acesso em: 20 jun.2005 às $10 \mathrm{~h} 30$.

\section{Abstract:}

\section{Collective Work transmuted into aid: (the contribution of the child to survive family nowadays)}

This research is about the child exploitation at work, nowadays, and seeks to characterize it and map it through research carried out with the Hospital Infantil Joana de Gusmao (HIJG). Our objective is problematizing current investigations on the object in question and indicate directions for future work. The research was conducted with semi-structured interviews made 106 immediate responsible by children, between five and 15 years, attending the emergence of HIJG. The seizure of the phenomenon has demanded that we exceeded its immediate appearance, locating the child in the context of capitalist social relations. It was not asking directly on the work that we have discovered child labor, but characterizing the aid infant family. We conclude that the exploitation of children in the work occurs in spaces sprayed integrating social work abstract, qualitatively different from that happened in the early days of the Industrial Revolution.

Keywords: Child exploitation at work. Social work abstract. Work. Aid.

Recebido em novembro de 2009.

Aceito em abril de 2010. 